\title{
Seasonal cercarial emergence patterns of Opisthorchis viverrini infecting Bithynia siamensis goniomphalos from Vientiane Province, Lao PDR
}

Nadda Kiatsopit ${ }^{1,2}$, Paiboon Sithithaworn ${ }^{1,2^{*}}$, Kulthida Kopolrat ${ }^{1,2}$, Ross H Andrews ${ }^{1,2,3,4}$ and Trevor N Petney ${ }^{3,5}$

\begin{abstract}
Background: Snail intermediate hosts play a pivotal role in maintaining the life cycles of trematodes, including Opisthorchis viverrini. We investigated the emergence patterns of $O$. viverrini cercariae infecting Bithynia siamensis goniomphalos at foci in an endemic area in Vientiane Province, Lao PDR.

Findings: Samples of B. s. goniomphalos collected during the hot-dry, rainy and cool-dry seasons were examined for $O$. viverrini infection by cercarial shedding. Emergence of cercariae from $O$. viverrini-positive snails was monitored daily from 06:00-18:00 h for seven consecutive days at 2 hourly intervals. Snail infections varied seasonally, being highest in the cool-dry season. Peak cercarial emergence was not consistent in different seasons, occurring between 08.00-10.00 $\mathrm{h}$ during the hot-dry season and between 12.00-14.00 $\mathrm{h}$ during the rainy and cool-dry seasons. The cercarial output was highest in the hot-dry season. The prevalence of infection and the emergence of cercariae were strongly dependent on snail size.

Conclusions: This study shows that size of snails and environmental factors (such as season) may affect the emergence patterns of cercariae of $O$. viverrini in snails. These results have both fundamental and applied implications for opisthorchiasis epidemiology and control.
\end{abstract}

Keywords: Opisthorchis viverrini, Bithynia siamensis goniomphalos, Cercarial emergence, Lao PDR

\section{Findings}

\section{Background}

The human liver fluke Opisthorchis viverrini is an important parasite endemic in Southeast Asian countries along the Mekong River, including Thailand, the Lao People's Democratic Republic (Lao PDR), southern Vietnam, and Cambodia [1]. An estimated eight million people in Thailand and two million people in Lao PDR are infected with $O$. viverrini $[2,3]$. Infection caused by this fluke is a major medical problem because it acts as a carcinogen that can cause bile-duct cancer (cholangiocarcinoma, CCA) [4]. Opisthorchis viverrini requires freshwater snails and cyprinid fish as first and second intermediate hosts, respectively, to complete its life cycle [5]. The

\footnotetext{
*Correspondence: paibsit@gmail.com

'Department of Parasitology, Faculty of Medicine, Khon Kaen University, Khon Kaen 40002, Thailand

${ }^{2}$ Liver Fluke and Cholangiocarcinoma Research Center (LFCRC), Faculty of Medicine, Khon Kaen University, Khon Kaen 40002, Thailand

Full list of author information is available at the end of the article
}

prevalence of infection in the fish hosts is usually very high [6], whereas infection rates in the snail hosts are very low $[7,8]$.

The transmission of many digeneans depends on the ability of the cercariae to invade specific hosts. Within snail hosts, the parasites multiply asexually and produce large numbers of cercariae. The biological characteristics of the cercariae, together with the environmental conditions, play a major role in trematode transmission [9]. Bithynia snails are the critical amplifying hosts for $O$. viverrini cercariae and thus are crucial to transmission. The natural prevalence of O. viverrini in Bithynia siamensis goniomphalos varies between sampling localities and times from $0.22 \%$ to $6.93 \%$ (mean of $3.03 \%$ ) in Thailand, and $0.37 \%$ to $8.37 \%$ (mean of $2.01 \%$ ) in the Lao PDR [7]. A study of the pattern of emergence of $O$. viverrini cercariae from infected B. s. goniomphalos in Thailand under natural conditions found a peak between 08:00-10:00 h with a maximum output of 1,728 cercariae per snail [10]. 
To date, the cercarial release of $O$. viverrini from $B . s$. goniomphalos from the Lao PDR has not yet been defined. Thus, the aim of this study was to assess the output and seasonal patterns of emergence of $O$. viverrini cercariae from B. S. goniomphalos originating from the Nam Ngum River wetland in Vientiane, Lao PDR.

\section{Methods \\ Sample collection}

Samples of B. s. goniomphalos $(\mathrm{n}=3,650)$ were collected on three occasions from Vientiane Province, Lao PDR: in April (hot-dry season, average temperature $=28.37^{\circ} \mathrm{C}$; average rainfall $=4.75 \mathrm{~mm}$; sunlight $=7.56 \mathrm{~h} /$ day; $\mathrm{n}=$ 3,267 ), October (rainy season, average temperature $=$ $27.68^{\circ} \mathrm{C}$; average rainfall $=6.44 \mathrm{~mm}$; sunlight $=5.89 \mathrm{~h} /$ day; $\mathrm{n}=180$ ) and November (cool-dry season; average temperature $=23.4^{\circ} \mathrm{C}$; average rainfall $=0.14 \mathrm{~mm}$; sunlight $=8.90 \mathrm{~h} /$ day; $\mathrm{n}=203$ ). Snails were collected by handpicking and dredging the sediment with a scoop from the same rice field. They were then cleaned, dried and placed into plastic bags and transported to the laboratory at Khon Kaen University where they were identified by standard morphological criteria [11-13]. The shell size (length and width) was measured.

\section{Screening of O. viverrini infection in B. s. goniomphalos}

Snail samples were kept under laboratory conditions for one day before screening started. Snails collected from each site were examined by the cercarial shedding method within two days to avoid effect of laboratory maintenance on cercarial emergence [7]. Each snail was placed separately into a small ( $3 \mathrm{~cm}$ in diameter, $2.5 \mathrm{~cm}$ in height) plastic container filled with dechlorinated tap water. The containers were covered with a lid studded with pins to prevent the snail from leaving. The snails were exposed to $1,200 \mathrm{~lx}$ lamps placed $30 \mathrm{~cm}$ above each container for $5 \mathrm{~h}$ during the day time at room temperature $\left(25 \pm 2^{\circ} \mathrm{C}\right)$. Opisthorchis viverrini cercariae were identified morphologically using light microscopy. To confirm this morphological identification, PCR analyses were conducted using an $O$. viverrini specific primer and previously published methods [14]. PCR assays were carried out in a final volume of $25 \mu \mathrm{l}$ consisting of PCR buffer $(10 \mathrm{mM}$ Tris $-\mathrm{HCl}$ [pH 9], $50 \mathrm{mM} \mathrm{KCl}, 1.5 \mathrm{mM} \mathrm{MgCl}_{2}$ ), $200 \mu \mathrm{M}$ each deoxynucleoside triphosphate, 1.5 U Taq DNA polymerase, and $1 \mu \mathrm{M}$ of each primers (pOV-6). Thermocycling conditions included an initial denaturation at $94^{\circ} \mathrm{C}$ for $5 \mathrm{~min}, 30 \mathrm{cy}$ cles of $94^{\circ} \mathrm{C}$ for $30 \mathrm{sec}$, annealing at $52^{\circ} \mathrm{C}$ for $30 \mathrm{sec}$, extension at $72^{\circ} \mathrm{C}$ for $45 \mathrm{sec}$, followed by a final extension step at $72^{\circ} \mathrm{C}$ for $10 \mathrm{~min}$. The amplified PCR products underwent electrophoresis using a $1.5 \%$ agarose gel containing $0.1 \mathrm{mg} / \mathrm{ml}$ ethidium bromide, and the gel was analyzed using the Gel Documentation System.

\section{Emergence of 0 . viverrini cercariae}

Opisthorchis viverrini-positive snails were maintained for one day in the dark until the experiment started. Infected snails from each sampling period were placed individually into a plastic container filled with $5 \mathrm{ml}$ dechlorinated tap water and exposed to light (1,200 lx lamp placed $30 \mathrm{~cm}$ above each container) from 06:00 to 18:00 $\mathrm{h}$ at room temperature $\left(25 \pm 2^{\circ} \mathrm{C}\right)$. Every $2 \mathrm{~h}$ the snails were removed to a new container and the cercariae released from each snail over the $2 \mathrm{~h}$ interval were counted under a dissecting microscope after staining with 1\% Lugol's iodine solution. At the end of the $12 \mathrm{~h}$ period, the snails were returned to the dark for $12 \mathrm{~h}$ and fed with ivy gourd leaves, Coccinia grandis. They were then exposed to light for $12 \mathrm{~h}$ the next day and this pattern continued for seven consecutive days. At the beginning of the new light phase, the containers were checked to determine that no cercariae were shed during the dark phase.

\section{Statistical test}

Raw data were entered into a Microsoft Excel spreadsheet and descriptive statistics were calculated using SPSS software v. 19.0 (IBM Software Company, USA). Statistical comparisons of cercarial release between different times calculated daily for 7 days and seasons were done using the Two-Related-Sample-Test followed by Wilcoxon Signed Ranks tests. Chi-square tests were used to assess the association of size factors with the prevalence of cercariae. Statistical comparisons of the daily cercarial emergence were done using the Mann-Whitney $U$ test. The results were considered significant when $\mathrm{P}$ was $<0.05$.

\section{Results}

The prevalence of infected snails was $0.21 \%, 5.00 \%$ and $8.37 \%$ for the hot-dry, rainy and cool-dry seasons, respectively. A peak in cercarial emergence was observed for the $12.00-14.00 \mathrm{~h}$ period in the rainy (mean number of cercariae $( \pm \mathrm{SD})=174 \pm 230$ cercariae $/$ snail $/ 2 \mathrm{~h} / \mathrm{d}$ ) and cool-dry (mean number of cercariae $=192 \pm 354$ cercariae/snail/2 h/d) seasons, whereas in the hot-dry season a peak in emergence was observed for the 08.00$10.00 \mathrm{~h}$ period (mean number of cercariae $=567 \pm 495$ cercariae/snail/2 h/d; Figure $1 \mathrm{~A}$ ). In addition, the snails collected during the hot-dry season showed an increase in cercarial emergence in the morning followed by a decline until evening, whereas emergence in the rainy and cool-dry seasons was lowest in early morning, peaked between $08.00-14.00 \mathrm{~h}$ before declining in late afternoon (Figure 1A). The cercarial emergence rates of $O$. viverrini calculated every 2 h from 06:00 until 18:00 h were significantly different between different times and seasons $(\mathrm{P}<0.05)$. The mean number of cercariae per snail per day was $263 \pm 54.8 \mathrm{cercariae} / \mathrm{snail} / \mathrm{d}$ for 6 snails in the hot-dry season, $98 \pm 75.73$ cercariae/snail/d for 9 snails 

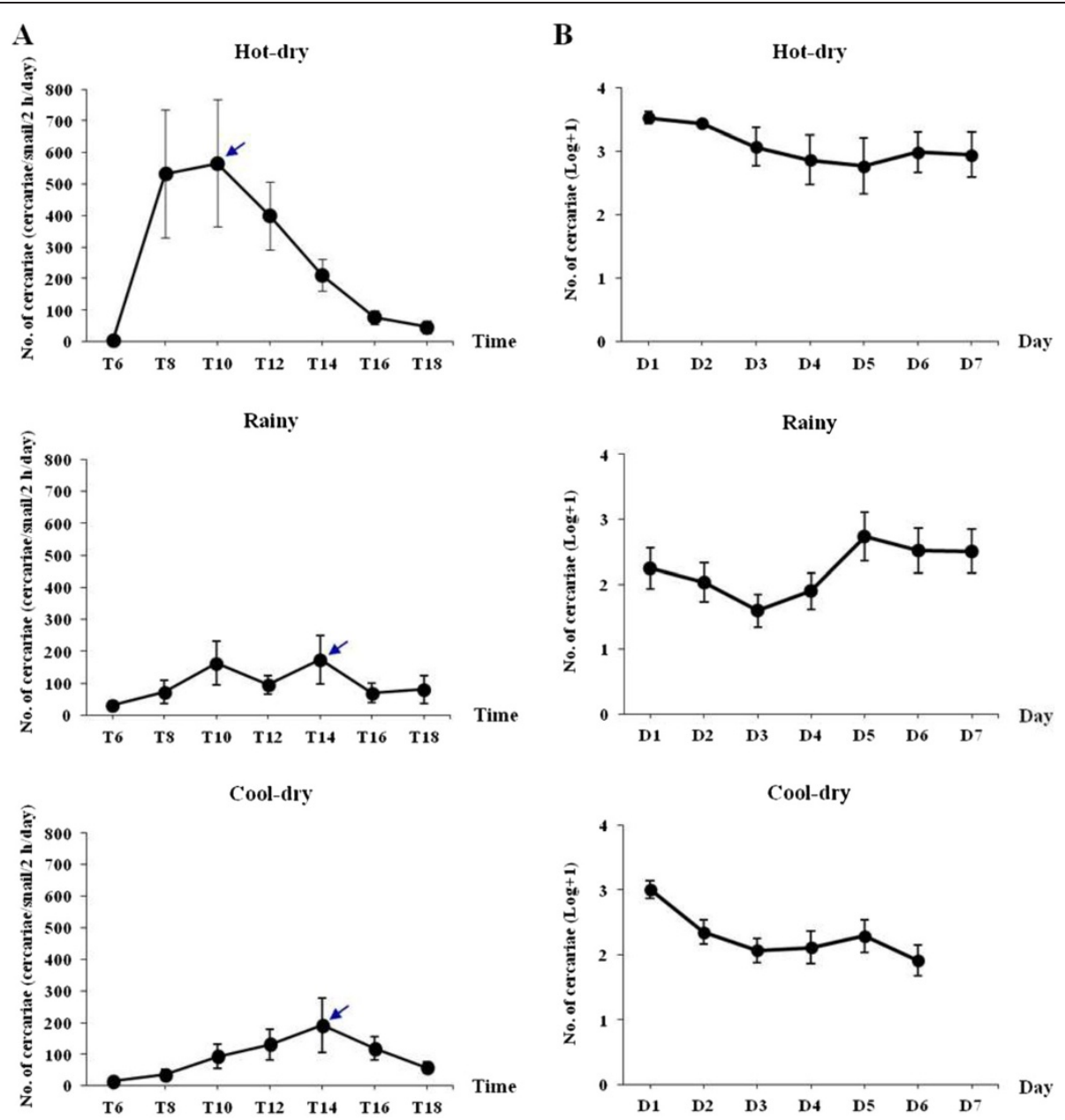

Figure 1 Cercarial emergence profiles of Opisthorchis viverrini infecting Bithynia siamensis goniomphalos. Cercarial emergence (A) calculated every $2 \mathrm{~h}$ from 06:00 until 18:00 $\mathrm{h}$ for 7 days (mean \pm SE) and (B) calculated daily for 7 days (mean \pm SE) from snails collected in Lao PDR.

in the rainy season, $91 \pm 67.61$ cercariae/snail/d for 17 snails in the cool-dry season. The daily cercarial output in both rainy and cool-dry seasons was low until the $3^{\text {rd }}$ day after the start of the experiment, increased during the next 2 days, and decreased during the subsequent 2 days (Figure 1B). In the hot-dry season, the number of cercariae decreased until the $5^{\text {th }}$ day, increased on the $6^{\text {th }}$ and decreased again on the $7^{\text {th }}$. Numbers of emerged cercariae of $O$. viverrini calculated daily for 7 days were significantly different between different days and seasons $(\mathrm{P}<0.05)$.

During the hot-dry season, there were no differences in the prevalence of infection between the small, mediumsized and large snails (Figure 2A). In the rainy season no large snails were collected but small snails had a significantly higher prevalence than the few medium-sized snails with respect to both length $\left(\chi_{2}^{2}=21.3, P<0.001\right)$ and width $\left(\chi_{2}^{2}=36.3, P<0.001\right)$. During the cool-dry season, there was a significantly higher cercarial prevalence in small compared to medium-sized snails with respect to both length $\left(\chi_{2}^{2}=4.9, \mathrm{P}<0.05\right)$ and width $\left(\chi_{2}^{2}=7.1, \mathrm{P}<0.01\right)$, and large snails with respect to width $\left(\chi_{2}^{2}=4.3, \mathrm{P}<0.05\right)$. There were no significant differences in the number of cumulative cercarial output with respect to the size of B. s. goniomphalos (Figure 2B and Mann-Whitney U tests; all values $\mathrm{P}>0.05$ ).

\section{Discussion}

Opisthorchis viverrini is a typical trematode undergoing asexual reproduction within snail hosts and emergence of the dispersal stages (cercariae) into the water bodies that subsequently infect cyprinid fishes, the second intermediate hosts. The output of cercariae from their snail hosts is a fundamental component of the transmission success in trematodes [15]. This study demonstrates a circadian rhythm in the emergence of the cercariae from their snail hosts, however, the maximum peak of emergence differs according to season. During the hot-dry season, maximum emergence occurs in the morning, whereas it occurs in the afternoon in the rainy and 

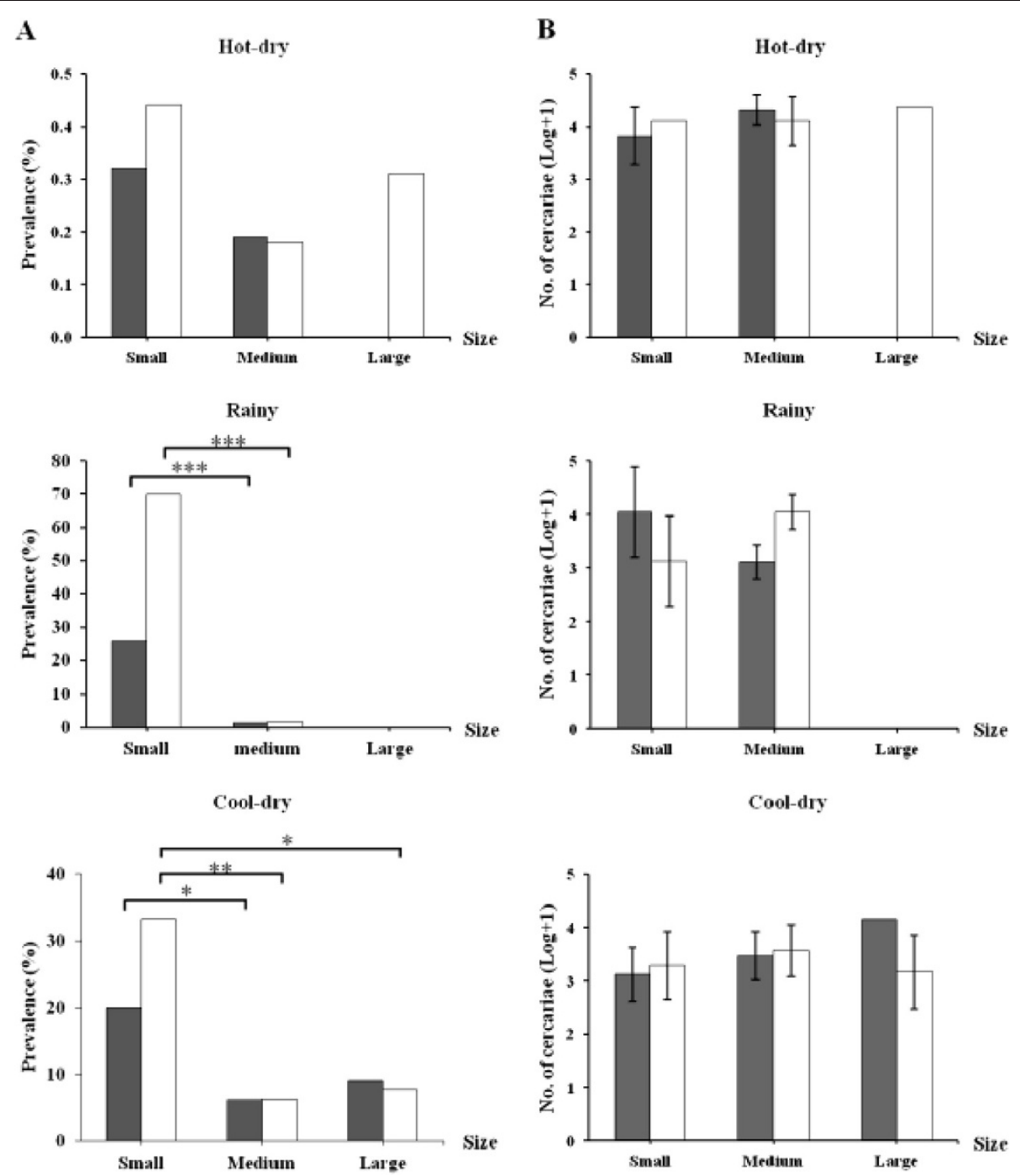

Figure 2 Relationship between the prevalence (A) and output (B) of Opisthorchis viverrini cercariae and shell-size of Bithynia siamensis goniomphalos. Mean values $( \pm 95 \% \mathrm{Cl}$ ) are shown. Black bars represent size-classes based on shell length ( $\mathrm{small}=<8.0 \mathrm{~mm}$, medium-sized $=$ 8.1-10.0 mm, large = >10.0 mm); white bars represent size-classes based on shell width ( $\mathrm{small}=<5.0 \mathrm{~mm}$, medium-sized =5.1-6.0 mm, large $=>6.0) .{ }^{*} \mathrm{P}<0.05,{ }^{* * P}<0.01,{ }^{* *} \mathrm{P}<0.001$. The absence of a bar reflects the lack of infected snails within the corresponding size-class collected.

cool-dry seasons. Temporal profiles of cercarial emergence of $O$. viverrini during the hot-dry season showed that maximum output occurred $4 \mathrm{~h}$ earlier than during the rainy and cool-dry seasons. In order to avoid possible effects of laboratory maintenance after collection from the field, the snails were processed for cercarial shedding on day 2 after collection and were fed with ivy gourd leaves daily at night time.

Opisthorchis viverrini shows a circadian rhythm of cercarial emergence. The adaptive importance of a rhythm in cercarial output is probably related to the facilitation of cercarial transmission to the vertebrate host, making cercarial emergence at different times advantageous [16]. For trematode cercariae, the time when the target host is likely to be present in the same locality is an obvious advantage
[17]. This is particularly relevant if one considers the short life-span and the decreasing infectivity of cercariae over time. Such a temporal pattern promotes a high degree of synchrony between parasites and their vertebrate hosts. The cercarial output of O. viverrini was higher during daytime, decreased during the evening and no cercariae emerged at night. Parasites may use a range of strategies to maximize transmission efficiency in an environment where the presence of the desired host is uncertain or temporally aggregated [18]. Alternatively, the observed higher output of cercariae during daytime, when most of the fish hosts are active $[19,20]$ and more likely to be exposed to cercariae, may increase parasite transmission efficiency.

The prevalence of $O$. viverrini in snails from the Lao PDR was highest in the cool-dry season. Similarly, our 
preliminary investigations indicate that the prevalence of O. viverrini in B. S. goniomphalos from Sakon Nakhon Province, Thailand tends to be high in the cool-dry months (Kopolrat et al., unpublished data). Whether this is in fact the case requires more intensive investigation. The faecal bacterial contamination in natural water reservoirs is an important indicator of seasonal transmission of $O$. viverrini eggs to snail intermediate hosts occurring in the rainy season [21]. After acquisition of infection, the snails require about two months for larval development before the emergence of free-swimming cercariae [22,23]. In addition, higher prevalence rates of $O$. viverrini infection in the snails in the cool-dry season corresponded to high burdens of $O$. viverrini in infected cyprinid fish in the late rainy and cool-dry seasons [24].

In our study, the cercarial output of O. viverrini was very high in the hot-dry season. Seasonal factors can affect the number of cercariae produced. For example, seasonal differences in the numbers of Schistosoma mansoni cercariae per Biomphalaria alexandrina in the Nile Delta were highest from June to September (summer) and declined to zero in February and March (winter and spring) [25]. Similarly, for both Rhipidocotyle fennica in clams and Diplostomun spathaceum in Lymnaea stagnalis in northern temperate climates the number of emerged cercariae was highest in late summer [26,27]. In a preliminary study by Kopolrat and others (unpublished data), O. viverrini cercarial output from B. s. goniomphalos collected from Sakon Nakhon Province at different times over a four year periods was highest in the hot-dry season (equivalent to summer) as is the case for the $O$. viverrini population from the Lao PDR studied here.

Cercarial output may be enhanced at higher temperatures and light as a simple consequence of increased host metabolic activity resulting in the greater energy resources available to the parasite $[15,28]$. Schmidt and Fried [29] found that the only significant factors in the emergence of Echinostoma trivolvis cercariae from naturally infected Helisoma trivolvis snails that were maintained under different laboratory conditions were temperature related. In their review, Galaktionov and Dobrovolskij [30] indicate that light and temperature are the predominant controlling factors for the emergence of cercariae. Kaewkes and others [31] found that a light intensity of $1,000 \mathrm{~lx}$ was the most important stimulus for O. viverrini cercariae emerging from naturally infected B. s. goniomphalos snails in the laboratory.

The rate of development of the trematode in its snail host is dependent on the access to ample supplies of food [32]. The feeding of snails accelerates parasite maturity so that at a given time many more mature cercariae are formed in well-fed, larger snails than smaller ones [33,34]. This is in contrast to the finding of Schmidt and Fried
[29] who studied cercarial output of E. trivolvis from naturally infected $H$. trivolvis snails maintained under different laboratory conditions and found that food had no affect on cercarial emergence. However, other factors such as the size of the snails can also affect cercarial output [7].

Our initial analyses indicate that there is a possible relationship between the prevalence of $O$. viverrini cercariae and shell size, with the prevalence of O. viverrini in small snails being significantly higher than in mediumsized and large snails. This could be a result of higher susceptibility to infection of smaller snails than of larger snails and also of parasite-induced snail mortality [35,36], as large snails may have acquired multiple infections or may have been infected for a longer period. The survival time of large snails (Lymnaea peregra) infected with Echinoparyphium recurvatum was found to be shorter than for small infected snails [37].

\section{Conclusions}

The size of the snails and environmental factors influencing cercarial emergence patterns were reported for the first time. The prevalence of $O$. viverrini in fieldcollected snail intermediate hosts, originating from Vientiane, Lao PDR was highest in the cool-dry season and commonly found in small snails. Cercarial output was highest in the hot-dry season. These results provide important fundamental and applied implications for control of opisthorchiasis in the Lao PDR. Whether these observed data are associated with different strains of O. viverrini s.l. in the Lao PDR and Thailand is not known. This hypothesis requires further investigation to compare the cercariae pattern of O. viverrini s.l. from Lao PDR and Thailand.

\section{Competing interests}

The authors declare that they have no competing interests.

\section{Authors' contributions}

NK performed sample collection, performed the experiments, examination of the samples, analyzed the results and prepared the manuscript. PS designed the study, performed sample collection, drafted the protocol and wrote the manuscript. KK performed sample collection. RHA wrote the manuscript. TNP analyzed the results and wrote the manuscript. All authors read and approved the final version of the manuscript.

\section{Acknowledgements}

We acknowledge the support of the Faculty of Medicine Khon Kaen University, Visiting International Professor Program. This work was supported by the Higher Education Research Promotion and office of the Higher Education Commission, through health cluster (SHeP-GMS), the Thailand Research Fund through the Basic Research Grant and Cholangiocarcinoma Screening and Care Program (CASCAP), Khon Kaen University. We would like to thank the Deutsche Forschungsgemeinschaft (PE1611/1-3), the National Research Council of Thailand, and the International Excellence Fund of Karlsruhe Institute of Technology as well as ASEAN-EU Year of Science, Technology and Innovation, 2012 for providing funding for cooperative workshops. 


\section{Author details}

${ }^{1}$ Department of Parasitology, Faculty of Medicine, Khon Kaen University, Khon Kaen 40002, Thailand. 'Liver Fluke and Cholangiocarcinoma Research Center (LFCRC), Faculty of Medicine, Khon Kaen University, Khon Kaen 40002, Thailand. ${ }^{3}$ Cholangiocarcinoma Screening and Care Program (CASCAP), Khon Kaen University, Khon Kaen 40002, Thailand. ${ }^{4}$ Imperial College London, Faculty of Medicine, St Mary's Campus, South Wharf Street, London W2 1NY, UK. ${ }^{5}$ Department of Ecology and Parasitology, University of Karlsruhe, Kornblumen Strasse 13, Karlsruhe 76131, Germany.

Received: 24 July 2014 Accepted: 20 November 2014

Published online: 02 December 2014

\section{References}

1. Andrews RH, Sithithaworn P, Petney TN: Opisthorchis viverrini: an underestimated parasite in world health. Trends Parasitol 2008, 24(11):497-501.

2. Sithithaworn P, Andrews RH, Petney TN, Saijuntha W, Laoprom N: The systematics and population genetics of Opisthorchis viverrini sensu lato: implications in parasite epidemiology and bile duct cancer. Parasitol Int 2012, 61(1):32-37.

3. Phongluxa K, Xayaseng V, Vonghachack Y, Akkhavong K, van Eeuwijk P, Odermatt P: Helminth infection in southern Laos: high prevalence and low awareness. Parasit Vectors 2013, 6(1):328.

4. Sithithaworn $P$, Yongvanit $P$, Duenngai $K$, Kiatsopit N, Pairojkul C: Roles of liver fluke infection as risk factor for cholangiocarcinoma. J Hepatobiliary Pancreat Sci 2014, 21(5):301-308.

5. Sithithaworn $P$, Andrews RH, Nguyen VD, Wongsaroj T, Sinuon $M$ Odermatt P, Nawa Y, Liang S, Brindley PJ, Sripa B: The current status of opisthorchiasis and clonorchiasis in the Mekong Basin. Parasitol Int 2012 61(1):10-16.

6. Saijuntha W, Sithithaworn P, Kaitsopit N, Andrews RH, Petney TN: Liver flukes: clonorchis and opisthorchis. Adv Exp Med Biol 2014, 766:153-199.

7. Kiatsopit N, Sithithaworn P, Saijuntha W, Boonmars T, Tesana S, Sithithaworn J, Petney TN, Andrews RH: Exceptionally high prevalence of infection of Bithynia siamensis goniomphalos with Opisthorchis viverrini cercariae in different wetlands in Thailand and Lao PDR. Am J Trop Med Hyg 2012 86(3):464-469.

8. Petney T, Sithithaworn P, Andrews R, Kiatsopit N, Tesana S, Grundy-Warr C Ziegler A: The ecology of the Bithynia first intermediate hosts of Opisthorchis viverrini. Parasitol Int 2012, 61(1):38-45.

9. Haas W: Physiological analyses of host-finding behaviour in trematode cercariae: adaptations for transmission success. Parasitology 1994, 109:S15-S29.

10. Phongsasakulchoti $P$, Sri-aroon P, Kerdpuech Y: Emergence of Opisthorchis viverrini cercariae from naturally infected Bithynia (Digoniostoma) siamensis goniomphalos. Southeast Asian J Trop Med Public Health 2005, 36(Suppl 4):189-191.

11. Brandt RAM: The non-marine aquatic Mollusca of Thailand. Archiv für Molluskenkunde 1974, 105:1-423.

12. Chitramvong YP: The Bithyniidae (Gastropoda: Prosobranchia) of Thailand:comparative external morphology. Malacol Rev 1992, 25:21-38.

13. Upatham ES, Sornmani S, Kitikoon V, Lohachit C, Bruch JB: Identification key for fresh-brackish water snails of Thailand. Malacol Rev 1983, 16:107-132.

14. Wongratanacheewin S, Pumidonming W, Sermswan RW, Maleewong W: Development of a PCR-based method for the detection of Opisthorchis viverrini in experimentally infected hamsters. Parasitology 2001, 122(Pt 2):175-180.

15. Poulin R: Global warming and temperature-mediated increases in cercarial emergence in trematode parasites. Parasitology 2006, 132(Pt 1):143-151.

16. Combes $C$, Bartoli $P$, Théron A: Trematode Transmission Strategies. In The Behavioural Ecology of Parasites. Edited by Lewis EE, Campbell JF, Sukhdeo MVK. London, UK: CABI Publishing; 2002:1-12.

17. Théron A, Combes C: Asynchrony of infection timing, habitat preference, and sympatric speciation of Schistosome parasites. Evolution 1995, 49(2):372-375.

18. Fenton A, Hudson PJ: Optimal infection strategies: should macroparasites hedge their bets? Oikos 2002, 96(1):92-101.

19. Helfman G: Fish Behaviour by Day, Night and Twilight. In The Behaviour of Teleost Fishes. Edited by Pitcher TJ. London: Croom Helm; 1986:366-387.
20. Wieser W: Physiological Energetics and Ecophysiology. In Cyprinid Fishes. Volume 3. Edited by Winfield IJ, Nelson JS. London: Chapman and Hall; 1991:426-455.

21. Kaewkes W, Kaewkes S, Tesana S, Laha T, Sripa B: Fecal bacterial contamination in natural water reservoirs as an indicator of seasonal infection by Opisthorchis viverrini in snail intermediate hosts. Parasitol Int 2012, 61(1):49-51.

22. Harinasuta C, Harinasuta T: Opisthorchis viverrini: life cycle, intermediate hosts, transmission to man and geographical distribution in Thailand. Arzneimittelforschung 1984, 34(9B):1164-1167.

23. Upatham ES, Viyanant V: Opisthorchis viverrini and opisthorchiasis: a historical review and future perspective. Acta Trop 2003, 88(3):171-176

24. Sithithaworn P, Pipitgool V, Srisawangwong T, Elkins DB, Haswell-Elkins MR: Seasonal variation of Opisthorchis viverrini infection in cyprinoid fish in north-east Thailand: implications for parasite control and food safety. Bull World Health Organ 1997, 75(2):125-131.

25. Chu KY, Dawood IK: Cercarial transmission seasons of Schistosoma mansoni in the Nile Delta area. Bull World Health Organ 1970, 42:575-580.

26. Taskinen J: Cercarial production of the trematode Rhipidocotyle fennica in clams kept in the field. J Parasitol 1998, 84(2):345-349.

27. Karvonen A, Savolainen M, Seppala O, Valtonen ET: Dynamics of Diplostomum spathaceum infection in snail hosts at a fish farm. Parasitol Res 2006, 99(4):341-345.

28. Mas-Coma S, Valero MA, Bargues MD: Climate change effects on trematodiases, with emphasis on zoonotic fascioliasis and schistosomiasis. Vet Parasitol 2009, 163(4):264-280

29. Schmidt KA, Fried B: Emergence of cercariae of Echinostoma trivolvis from Helisoma trivolvis under different conditions. J Parasitol 1996, 82(4):674-676

30. Galaktionov KV, Dobrovolskij AA: The Biology and Evolution of Trematodes. Boston, Dordrecht, London: Kluwer Academic; 2003.

31. Kaewkes S, Kaewkes W, Boonmars T, Sripa B: Effect of light intensity on Opisthorchis viverrini cercarial shedding levels from Bithynia snails-a preliminary study. Parasitol Int 2012, 61(1):46-48.

32. Kendall SB: Nutritional factors affecting the rate of development of Fasciola hepatica in Limnaea truncatum. J Helminthol 1949, 23(3-4):179-190.

33. Belfaiza M, Rondelaud D, Moncef M, Dreyfuss G: Fasciola hepatica: the effect of food quality on the development of redial generations in Galba truncatula infected with allopatric miracidia. Parasitol Res 2004, 92(1):12-17.

34. Seppala O, Liljeroos K, Karvonen A, Jokela J: Host condition as a constraint for parasite reproduction. Oikos 2008, 117:749-753.

35. Fredensborg BL, Mouritsen KN, Poulin R: Impact of trematodes on host survival and population density in the intertidal gastropod Zeacumantus subcarinatus. Mar Ecol Prog Ser 2005, 290:109-117.

36. Sorensen RE, Minchella DJ: Parasite influences on host life history: Echinostoma revolutum parasitism of Lymnea elodes snails. Oecologia 1998, 115:188-195.

37. Morley NJ, Adam ME, Lewis JW: The effects of host size and temperature on the emergence of Echinoparyphium recurvatum cercariae from Lymnaea peregra under natural light conditions. J Helminthol 2010, 84(3):317-326

doi:10.1186/s13071-014-0551-

Cite this article as: Kiatsopit et al: Seasonal cercarial emergence patterns of Opisthorchis viverrini infecting Bithynia siamensis goniomphalos from Vientiane Province, Lao PDR. Parasites \& Vectors 2014 7:551. 